\title{
○ Echocardiographic Characterization of Female Professional Basketball Players in the US
}

\author{
JAMA Cardiol. 2020; 5(9):991-998.
}

\section{Prof. Doutor Hélder Dores}

Hospital da Luz Lisboa. Human Performance Department - Sport Lisboa e Benfica. NOVA Medical School. Lisboa

Este estudo publicado no JAMA Cardiology, por Shames S e colegas, teve como objetivo principal avaliar a estrutura e a função cardíaca por ecocardiograma transtorácico em basquetebolistas do género feminino. A sua relevância prende-se com a escassez de dados sobre a remodelagem cardíaca nestas atletas, sub-representadas nos estudos prévios, comparativamente a atletas do género masculino. A ausência de valores de referência, especificamente em basquetebolistas e atletas com área de superficial corporal (ASC) semelhante, dificulta o diagnóstico diferencial entre remodelagem fisiológica e patológica, sobretudo miocardiopatias.

Neste estudo transversal foram incluídas 140 basquetebolistas da Women's National Basketball Association (WNBA), na época de 2017, $75 \%$ afro-americanas, idade média $26,8 \pm 3,9$ anos, estatura $=183 \pm 9 \mathrm{~cm}$; ASC $2,02 \pm 1,18 \mathrm{~m}^{2}$. Na avaliação pré-competitiva realizaram ecocardiograma transtorácico e de exercício, interpretados segundo as recomendações da American Society of Echocardiography e European Association of Cardiovascular Imaging.

Das atletas estudadas, 26\% e $42 \%$ tinham, respetivamente, dimensões aumentadas do ventrículo esquerdo (VE) e do ventrículo direito (VD), com relação linear entre dimensões e ASC. A espessura parietal máxima do VE variou entre 6-14mm, 56\% com espessura $10 \mathrm{~mm}$, mas apenas numa atleta $>13 \mathrm{~mm}$. Relativamente à geometria do VE, a maioria das atletas (64\%) tinha geometria normal, 16\% hipertrofia (sobretudo excêntrica, $11 \%$ us. $5 \%$ concêntrica) e 19\% remodelagem concêntrica. O diâmetro médio da raiz da aorta foi igual a $31 \mathrm{~mm}$ e houve apenas duas atletas com dimensões aumentadas. A aurícula esquerda encontrava-se dilatada em $18 \%$ e a direita em $41 \%$ das atletas. Em termos funcionais, a fração de ejeção VE foi <52\% em 15\% das atletas, normalizando em todas durante o exercício.

Como conclusões, os autores salientam: 1) o aumento das dimensões das cavidades cardíacas é frequente em atletas da WNBA; 2) as alterações estruturais são influenciadas pela ASC e remodelagem fisiológica; 3) o estudo pode contribuir para a definição de valores de referência para a remodelagem cardíaca em basquetebolistas de elite do género feminino.

\section{Comentário}

Apesar de existirem poucos dados sobre os parâmetros ecocardiográficos em atletas do género feminino, estes resultados não são muito surpreendentes. Contrariamente ao reportado previamente, em que a influência do género na remodelagem cardíaca era muito marcada, esta diferença tem-se diluído nos últimos estudos, porque as exigências e as características do exercício são cada vez mais semelhantes entre o desporto feminino e o masculino.

A prevalência das adaptações cardíacas estruturais não difere da descrita em atletas do género feminino de outras modalidades, mas uma especificidade desta população é o facto das medições indexadas à ASC serem maioritariamente normais. Por outro lado, da mesma forma do descrito em basquetebolistas do género masculino, é frequente a presença de dimensões aumentadas.
Contudo, uma diferença importante é o facto de nas mulheres ser pouco frequente $o$ aumento da espessura parietal, devendo uma espessura $>12 \mathrm{~mm}$ motivar avaliação adicional para excluir patologia subjacente. Outro dado interessante é a confirmação da remodelagem do VD pela influência mista de exercício dinâmico e estático nesta modalidade. Outra particularidade em basquetebolistas, nomeadamente nas atletas mais altas, é a suspeita da síndrome de Marfan, sendo crucial a avaliação cuidada da artéria aorta. A dilatação da aorta é muito rara em atletas, não sendo uma adaptação fisiológica e justificando investigação adicional.

Entre as limitações do estudo destacam-se a reduzida dimensão da amostra, o viés de seleção nas características étnicas, maioritariamente de origem africana, não permitindo generalizar os resultados, e a ausência de um grupo controlo com ajuste para altura e ASC.

Em suma, este estudo demonstra que a remodelagem cardíaca é muito frequente em basquetebolistas do género feminino, com alguns parâmetros dentro dos critérios de diagnóstico de miocardiopatias, justificando na sua análise a integração de múltiplas características, incluindo da atleta e do desporto praticado. Salienta-se que, apesar da sua utilidade e relevância, a realização do ecocardiograma transtorácico em atletas requer diferenciação para reduzir os casos falsos positivos decorrentes da interpretação errada destas adaptações fisiológicas como patológicas.
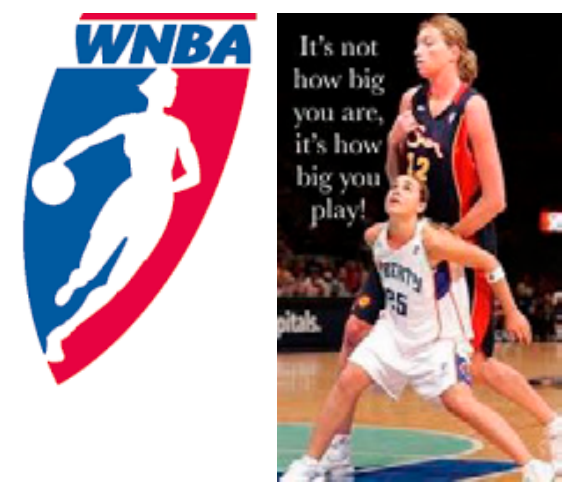